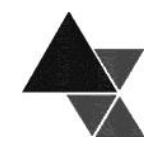

Nota Técnica

\title{
A agricultura familiar produz $70 \%$ dos alimentos consumidos no Brasil?
}

\section{Rodolfo Hoffmann ${ }^{1}$}

Autoridades afirmaram que a agricultura familiar produz 70\% dos alimentos consumidos no Brasil. A afirmativa é falsa. O valor monetário de toda a produção da agricultura familiar corresponde a menos de $25 \%$ do total das despesas das famílias brasileiras com alimentos.

Palavras-chave: agricultura familiar, produção de alimentos, consumo de alimentos, Brasil.

\section{Family farms produce $\mathbf{7 0} \%$ of the food consumed in Brazil?}

Public authorities have declared that family farms produce $70 \%$ of the food consumed in Brazil. The statement is false. The monetary value of all family farm production represents less than $25 \%$ of total expenditure of Brazilian families with food.

Key-words: family farms, food production, food consumption, Brazil.

${ }^{1}$ Professor Sênior da Escola Superior de Agricultura "Luiz de Queiroz" (ESALQ), Universidade de São Paulo (USP), com apoio do CNPq. O autor agradece a colaboração de Mirian Rumenos Piedade Bacchi e os comentários de Antonio Florido, Marcela N. Ferrario, Henrique C. Kawamura e Josimar G. de Jesus. Correspondência: ESALQ-LES, Cx. Postal 9. CEP 13.418-900. Piracicaba-SP. E-mail: hoffmannr@usp.br. 
Em 27/07/2011 o Portal Brasil [1] publicou a notícia intitulada "Agricultura familiar produz 70\% de alimentos do País, mas ainda sofre na comercialização". Afirma-se, no texto, que:

Apesar de ser responsável pela produção de $70 \%$ dos alimentos do País, a agricultura familiar enfrenta desafios na comercialização e organização de sua produção. A avaliação é do secretário de Agricultura Familiar do Ministério do Desenvolvimento Agrário, Laudemir Müller, ...

O valor da porcentagem é repetido em notícia do Portal Planalto [2] de 05/06/2012, com o título "Agricultura familiar já produz $70 \%$ dos alimentos consumidos no mercado interno do País, informa Pepe Vargas". Na ocasião, Pepe Vargas era o ministro do Desenvolvimento Agrário.

Depois essa "estimativa" de $70 \%$ é repetida em vários documentos, incluindo trabalhos acadêmicos. O texto sobre "Agricultura familiar" na Wikipédia [3], por exemplo, reproduz, sem crítica, a afirmativa de que "A agricultura familiar é responsável por cerca de $70 \%$ dos alimentos produzidos no Brasil", citando a notícia do Portal Brasil de 27/07/2011.

Não foi possível localizar um documento mostrando como foi estimada essa porcentagem (70\%).

É espantosa a reprodução sem crítica da porcentagem porque a afirmativa, em si, não faz sentido. Falar em " $70 \%$ dos alimentos" torna necessário definir o total de alimentos. Somam-se toneladas de soja com toneladas de uva e toneladas de açúcar? Toneladas de açúcar ou toneladas de cana-deaçúcar? Toneladas de trigo, de farinha de trigo ou de pão? Toneladas de soja ou de óleo de soja? Dada a grande heterogeneidade dos alimentos, é um absurdo somar as quantidades físicas.

Também é necessário definir o que se entende por "agricultura familiar", pois não se trata de um conceito universal. No Brasil, atualmente, é razoável admitir, salvo especificação em contrário, que se utiliza a definição da Lei no 11.326, de 24 de julho de 2006. Essencialmente, a definição é a seguinte:

Art. $3^{\circ}$. Para os efeitos desta Lei, considera-se agricultor familiar e empreendedor familiar rural aquele que pratica atividades no meio rural, atendendo, simultaneamente, aos seguintes requisitos:
I - não detenha, a qualquer título, área maior do que 4 (quatro) módulos fiscais;

II - utilize predominantemente mão de obra da própria família nas atividades econômicas do seu estabelecimento ou empreendimento;

III - tenha renda familiar predominantemente originada de atividades econômicas vinculadas ao próprio estabelecimento ou empreendimento;

IV - dirija seu estabelecimento ou empreendimento com sua família.

Informações complementares podem ser obtidas em IBGE (2009) [4] e França et al. (2009) [5]. Esse último texto discute as diferenças entre a atual definição legal e o conceito usado anteriormente em estudo da Food and Agricultural Organization/Instituto Nacional de Colonização e Reforma Agrária (FAO/INCRA).

Adotando a definição legal de agricultura familiar, o IBGE destacou, nos resultados do Censo Agropecuário de 2006, a contribuição da agricultura familiar. A primeira versão dos resultados foi publicada em 2009. Posteriormente o IBGE elaborou uma "Segunda Apuração" de todos os dados, que foi divulgada em 2012. Os novos resultados referentes à agricultura familiar não foram publicados em papel, mas estão disponíveis no site do IBGE [0. Essa é a fonte dos dados apresentados na Tabela 1 , na qual se verifica que, no Brasil, em 2006, a agricultura familiar participou com $83,2 \%$ da produção de mandioca, $69,6 \%$ da produção de feijão (agregando todos os tipos), 33,1\% da produção de arroz em casca e $14,0 \%$ da produção de soja.

Além disso, os dados da segunda apuração do Censo Agropecuário de 2006 mostram que 29,7\% do número de cabeças de bovinos, $51,2 \%$ das aves e $59,0 \%$ dos suínos pertencem à agricultura familiar, na qual trabalham 12,3 milhões de pessoas.

Não é necessário criar "estatísticas" sem sentido para mostrar a importância da agricultura familiar no Brasil. 
Tabela 1. Produção da agricultura familiar e da não familiar para produtos selecionados. Brasil, 2006

\begin{tabular}{|c|c|c|c|}
\hline Produto & $\begin{array}{l}\text { Produção não } \\
\text { familiar }\end{array}$ & Produção familiar & $\begin{array}{c}\text { Participação da agricultura } \\
\text { familiar }(\%)\end{array}$ \\
\hline Arroz em casca (1.000 t) & 6.484 & 3.204 & 33,1 \\
\hline Feijão-preto (1.000 t) & 160 & 512 & 76,2 \\
\hline Feijão de cor $(1.000$ t) & 595 & 685 & 53,5 \\
\hline Feijão-outros $^{1}(1000$ t) & 184 & 953 & 83,8 \\
\hline Feijão-total (1.000 t) & 939 & 2.149 & 69,6 \\
\hline Mandioca $(1.000 \mathrm{t})$ & 2.006 & 9.907 & 83,2 \\
\hline Milho em grão (1.000 t) & 22.555 & 18.873 & 45,6 \\
\hline Soja $(1.000 \mathrm{t})$ & 39.731 & 6.465 & 14,0 \\
\hline Trigo $(1.000 \mathrm{t})$ & 1.760 & 473 & 21,2 \\
\hline Café em grão (verde) (1000 t) & 1.502 & 919 & 38,0 \\
\hline Leite de vaca (106 litros) & 8.719 & 11.849 & 57,6 \\
\hline Leite de cabra (106 litros) & 12 & 24 & 67,1 \\
\hline Ovos de galinha (106úzias) & 2.231 & 451 & 16,2 \\
\hline
\end{tabular}

Fonte: IBGE [6].

${ }^{1}$ Feijão-fradinho, caupi, de corda ou macáçar, em grão.

Se, para o feijão considerarmos o agregado dos diversos tipos, entre os produtos considerados na Tabela 1 o único para o qual a contribuição da agricultura familiar ultrapassa $70 \%$ é a mandioca. Mas se trata de participação na produção total dessa lavoura, e não da contribuição para a alimentação dos brasileiros.

Os dados da Pesquisa de Orçamentos Familiares (POF) 2008-2009 permitem avaliar a contribuição dos diversos alimentos para a nutrição dos brasileiros. Para uma amostra de pessoas de 10 anos ou mais foi registrado o consumo de todos os alimentos ao longo de 24 horas. O IBGE também fornece uma tabela que permite calcular a energia e os nutrientes fornecidos por cada alimento. Considerando os alimentos constituídos essencialmente por mandioca (aipim, macaxeira, tapioca, farinha de mandioca, etc.) verifica-se que eles fornecem apenas $2,3 \%$ da energia total dos alimentos consumidos ${ }^{2}$.

Considerando os diversos tipos de arroz e as preparações à base de arroz, verifica-se que fornecem $12,9 \%$ da energia total dos alimentos consumidos. Essa porcentagem é igual a $11,2 \%$ para os diversos tipos de feijão e as preparações à base de feijão e é $9,0 \%$

${ }^{2}$ Foram utilizados, para cada pessoa, apenas os dados do 1ํ dia de registro do consumo, como feito pelo próprio IBGE. considerando os diversos tipos de pão de sal, exclusive o pão de milho, mostrando a importância do trigo na alimentação do brasileiro.

É óbvio que uma avaliação completa da importância da mandioca para a alimentação dos brasileiros exigiria considerar a sua contribuição no fornecimento de proteínas, lipídios, etc. Mas o objetivo dessa nota é apenas mostrar que não há justificativa possível para o mito dos " $70 \%$ ".

No que se refere à mandioca, cabe ressaltar que ela é muito importante na alimentação dos próprios agricultores familiares. Trata-se de uma lavoura rústica e, para o pequeno agricultor familiar, o produto fica "armazenado" na roça e, quando necessário, ele arranca um ou mais pés de mandioca. Os dados do Censo Agropecuário de 2006 indicam que apenas $48,9 \%$ da produção de mandioca da agricultura familiar é vendida; mais da metade é consumida ou processada no próprio estabelecimento.

Em uma análise econômica, podemos agregar produtos heterogêneos considerando o seu valor de mercado. Os dados do Censo Agropecuário de 2006 tabulados pelo IBGE mostram que o valor anual da produção da agricultura familiar é 54,5 bilhões de reais 
(33,2\% do total) e o da agricultura não familiar é 109,5 bilhões $(66,8 \% \text { do total })^{3}$.

Com base em tabulações especiais do Censo Agropecuário de 2006, Kageyama et al. [7] estimam que a agricultura familiar contribui com $52 \%$ do valor da produção, mas seu conceito de agricultura familiar é bem mais abrangente do que o da Lei no 11.326: foi considerado familiar todo estabelecimento no qual pelo menos metade da mão de obra utilizada fosse familiar, sem restrições relativas a sua área total ou à origem da renda familiar.

Também podemos avaliar a importância da agricultura familiar comparando o valor da sua produção com o total da despesa com alimentação das famílias do País. De acordo com os dados da POF 2008-2009, o total da despesa anual com alimentos, em reais de janeiro de 2009, era 292,6 bilhões ${ }^{4}$.

Se admitirmos que não há exportação de nenhum produto da agricultura familiar $e$ considerarmos uma inflação de $15 \%$ entre o ano do Censo Agropecuário (2006) e janeiro de 2009, verificase que a produção da agricultura familiar corresponde a $21,4 \%$ do valor total das despesas com alimentos das famílias do País ${ }^{5}$. Para entender essa porcentagem é necessário ter em mente que, quando alguém compra alimentos em um supermercado ou uma família almoça em um restaurante, a despesa com alimentos inclui o pagamento de custos de processamento e serviços que fazem com que essa despesa possa superar em muito o valor dos produtos agropecuários que deram origem aos alimentos.

É praticamente impossível avaliar, com precisão razoável, qual é a parcela da matéria-prima usada na produção dos alimentos consumidos no Brasil que se origina da produção da agricultura familiar. Seria necessário analisar, pormenorizadamente, os canais de comercialização de todos os alimentos e das respectivas matérias-primas. Além disso, de um ponto de vista econômico, não é correto considerar apenas os fluxos físicos de mercadorias.
A farinha de trigo é ingrediente básico de muitos alimentos, fazendo com que o trigo seja um produto agrícola cuja contribuição para a energia total dos alimentos consumidos no Brasil seja similar à do arroz. Geralmente o País precisa importar mais do que produz para atender a demanda por trigo. Se as divisas necessárias à importação de trigo são obtidas, em parte, por meio da exportação de soja, percebe-se que a exportação de soja é, sim, uma maneira de obter os alimentos consumidos no Brasil ${ }^{6}$.

Como neto de imigrantes alemães que criaram seus filhos no Brasil com base na agricultura familiar, nada mais distante das intenções de quem escreve do que reduzir a importância que o leitor atribui à agricultura familiar. Mas a afirmativa de que "A agricultura familiar produz $70 \%$ dos alimentos consumidos no Brasil" não tem base e, pior, não tem sentido. $O$ reconhecimento da importância da agricultura familiar no Brasil não precisa de dados fictícios.

\section{REFERÊNCIAS}

[1] Portal Brasil. Agricultura familiar produz $70 \%$ de alimentos do País mas ainda sofre na comercialização [acesso em 27 jul 2011]. Disponível em: www.brasil.gov.br

[2] Portal Planalto. Agricultura familiar já produz $70 \%$ dos alimentos consumidos no mercado interno do país, informa Pepe Vargas [acesso em 05 jun 2012]. Disponível em: www2.planalto.gov.br

[3] Wikipédia. Agricultura familiar [acesso em 4 jul 2014]. Disponível em: http://pt.wikipedia.org

[4] Instituto Brasileiro de Geografia e Estatística. Censo Agropecuário 2006 - Agricultura Familiar - Primeiros Resultados - Brasil, Grandes Regiões e Unidades da Federação. Rio de Janeiro: Instituto Brasileiro de Geografia e Estatística, 2009.

[5] França CG, Del Grossi ME, Marques VPMA. O Censo Agropecuário 2006 e a agricultura familiar no Brasil. Brasilia: Ministério do Desenvolvimento Agrário, 2009.

\footnotetext{
${ }^{3}$ Do total de 4.366 mil estabelecimentos de agricultura familiar registrados no Censo Agropecuário de 2006, mais de $10 \%$ não informaram nenhum valor de produção. Dos 4.639 mil estabelecimentos agtopecuários com valor de produção, 3.903 mil são classificados como agricultura familiar e 736 mil como agricultura não familiar.

${ }^{4}$ São 5.817 mil familias com uma despesa média mensal com alimentação de $\mathrm{R} \$ 421,72$.

${ }^{5}$ Evidentemente essa porcentagem será ainda menor se descontarmos a exportação de produtos da agricultura familiar.
}

\footnotetext{
6 Não esquecer que a soja também é matéria-prima para alimentos consumidos no Brasil. Conforme dados da POF 2008-2009, o óleo de soja corresponde a quase $90 \%$ do volume de óleos comestíveis adquiridos pelos domicílios do País.
} 
[6] Instituto Brasileiro de Geografia e Estatística. Censo Agropecuário 2006. Agricultura Familiar - Brasil, Grandes Regiões e Unidades da Federação. Primeiros Resultados [acesso em 1 maio 2014]. Disponível em: www.ibge.gov.br/home/estatistica/economia/agropecuaria/ censoagro/agri_familiar_2006_2/default.shtm
[7] Kageyama AA, Bergamasco SMPP, Oliveira JTA. Uma tipologia dos estabelecimentos agropecuários do Brasil a partir do Censo de 2006. Revista de Economia e Sociologia Rural 2013;51(1):105-122. 